\title{
Research on the Influence of Big Data on Higher Education Based on Feasibility
}

\section{Xueyan Li}

Zibo Vocational Institute, Zibo City 255000, Shandong Province, China

Abstract: With the rapid development, human society has entered the era of big data, which has a huge impact on higher education. With the rapid development of information technology in China, higher education has increased the variety and quantity, which speeds up the interaction between information and data. Based on massive information data, big data promotes the development of the world, which has changed the traditional higher education. With the combination of big data and higher education, universities can better promote the governance transformation of higher education. Based on the feasibility of big data, this paper analyzes the impact of big data on higher education. Through big data, colleges can carry out diversified education, which will change the main ideological mode and governance mode of traditional higher education. By strengthening big data literacy, China's higher education can strengthen the construction of data culture, which will build a scientific management model.

Keywords: Feasibility; Big Data; Higher Education; Impact

\section{Introduction}

With the acceleration of the internationalization process, the higher education in China is developing continuously, which has caused the important construction of modern education in China. Through the feasibility of big data, higher education will be more intelligent and humanized, which will become the management goal of higher education in the future. Therefore, higher education should actively establish the awareness of big data, which will deepen the connotation of big data. By adhering to the people-oriented principle, big data will be organically integrated into higher education, which will optimize the education management mode and system. Through big data, full play to the role and value can be given, which will promote the management and development of colleges and colleges can cultivate higher quality talents. Big data will have a significant impact on higher education, which will improve the education model of colleges. Based on the feasibility analysis, big data will improve the diversified development of higher education, which will build an information platform.

\section{The impact of big data on higher education}

Under the background of big data, great changes have taken place in higher education. Big data has an important impact on higher education, as shown in Figure 1.

Copyright (C) 2020 Xueyan Li

doi: $10.18282 /$ le.v9i3.824

This is an open-access article distributed under the terms of the Creative Commons Attribution Non-Commercial License

(http://creativecommons.org/licenses/by-nc/4.0/), which permits unrestricted non-commercial use, distribution, and reproduction in any medium,

provided the original work is properly cited. 


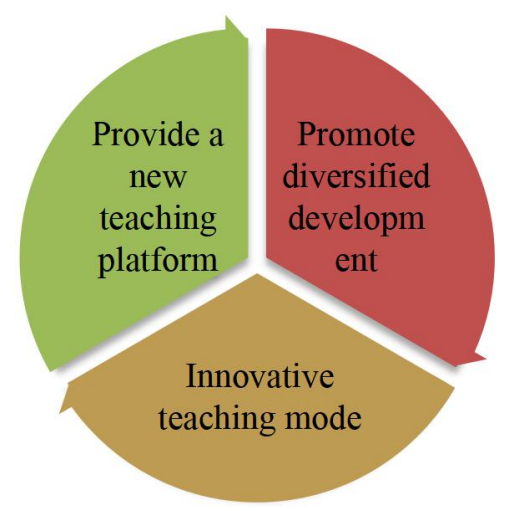

Figure 1. The impact of big data on higher education.

\subsection{Promote diversified development}

Under the background of big data, great changes have taken place in higher education, which will effectively promote the diversified development. With the advantages of big data, the relevance and openness of big data will build an important platform, which will improve the diversified platform of higher education. Through big data thinking, the integrity and relevance of higher education can be better understood, which lays the foundation for the diversified development of colleges. Through big data, universities can process information step by step, which will improve the efficiency and openness of higher education. By changing to diversification, the governance subject of colleges can be promoted, which will expand to colleges, social organizations and the public.

\subsection{Provide a new teaching platform}

In the 21 st century, information technology has perfected a new direction for our learning platform, which has realized the modern characteristics of intelligent learning platform. Through the construction of a new teaching platform, the traditional teaching mode should be broken through, which will be able to achieve not limited by the region and curriculum time. Through the new teaching platform, a new talent training mode has been changed. By improving the learning quality of students, the training plan of high-quality talents can be promoted. Through information coverage, higher education information can be integrated from all over the world, which will enhance the connection between colleges. Through the agreement, colleges can build a common education platform, which will realize the resource sharing of higher education. By providing a full range of education and teaching services, students can use fragmented time to learn any course.

\subsection{Innovative teaching mode}

Through big data, the teaching mode will effectively break through the traditional teaching mode, which will provide an innovative and scientific teaching form. Through big data, higher education teaching will break the limitations of traditional education teaching, which will reduce the impact of time and space on students' learning. Through big data, colleges can provide rich teaching resources, which will optimize the teaching mode of higher education. Through big data, colleges can strengthen exchanges and cooperation between higher education, which will improve the convenience and efficiency of higher education. Through big data, book information can be shared, which improves the efficiency of data query.

\section{Higher education based on big data}

This paper is based on the field survey. 1000 formal questionnaires were sent out, 988 effective questionnaires were sent out. The effective rate was $98.8 \%$.

\subsection{Limitations of big data}


Higher education is big data of educational information, including teaching, scientific research, management data, and so on, which contains great value. Through the big data platform, colleges can reflect the teaching and research management of higher education in real time. However, these data still have many problems. According to the survey results, the main problem is low data quality, accounting for $66.2 \%$. The second is complex data sources, accounting for 62.4\%. Details are shown in Figure 2.

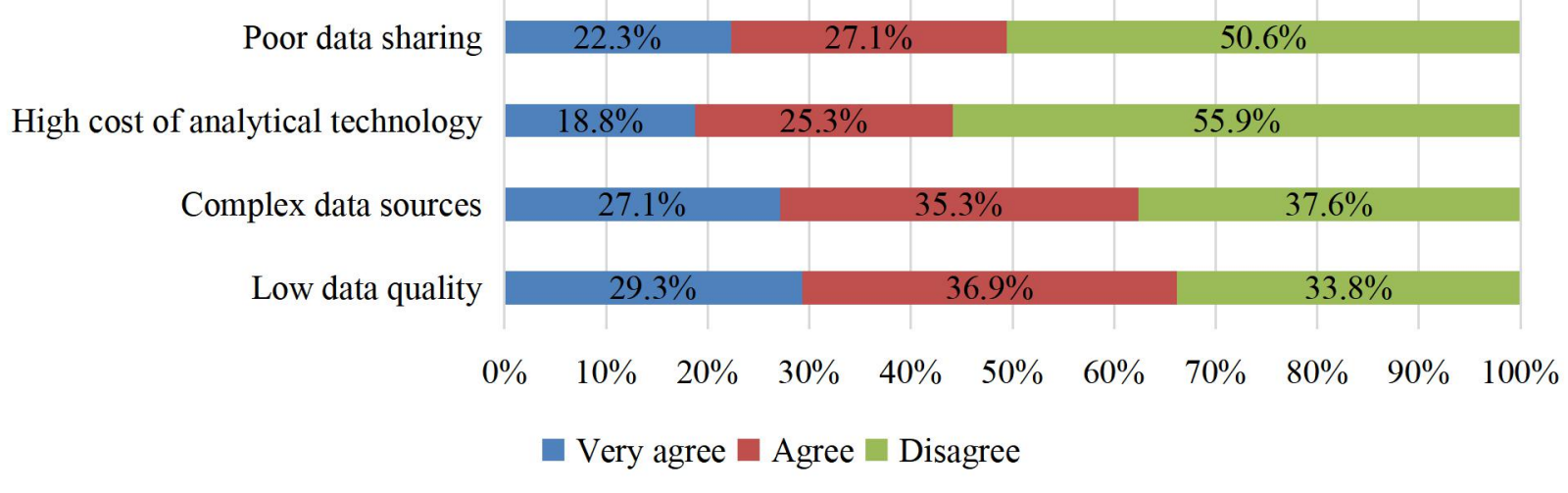

Figure 2. Limitations of big data.

\subsection{Resistance of higher education environment}

Big data is a new technology, which is imperfect in theory and technology. Although university big data has made obvious progress, it still needs to adhere to the traditional education. According to the survey results, the main problem is questioning the rationality of big data, accounting for $63.4 \%$. The second is not recognize big data, accounting for 56.1\%. Details are shown in Figure 3.

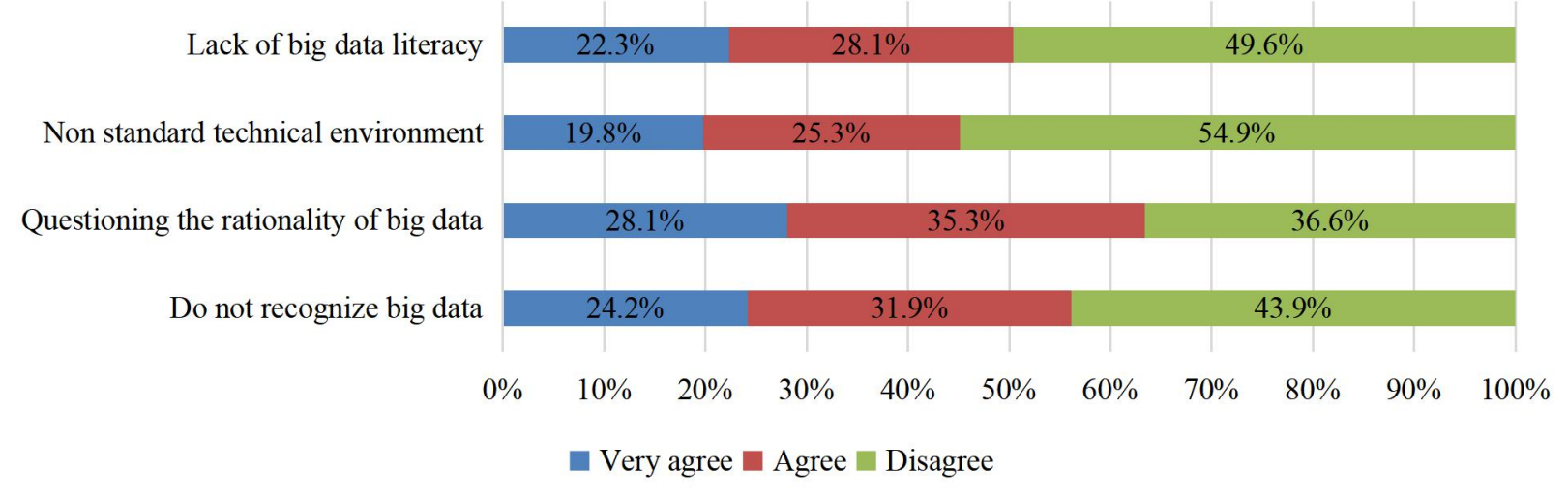

Figure 3. Resistance of higher education environment.

\section{Measures to promote big data in higher education}

\subsection{Reasonable promotion of big data}

Through big data, students can fully understand and rationally choose their own work, which will effectively solve the problem of higher education. By vigorously promoting big data, the influence of big data can be promoted. By transforming the original data application, the application of big data can be simplified. With MOOCS, technical data can be analyzed in real time, which can improve the scale and diversity of learners. Through big data improvement, large-scale data storage that describes the analysis and differentiation of distance education learning can be achieved. Through the development of personalized learning programs, big data platform can get the change curve of learners' 
attitude, focus, interest and performance, which will better grasp the learning law of learners. Therefore, universities must reasonably promote big data, which will realize scientific teaching.

\subsection{Integrate data resources}

Universities should integrate data resources, which will establish a big data application platform. By integrating the original information system data resources, the data resources of teachers and students that realize the large-scale integration of university data resources can be analyzed and processed. Big data application platform will include many contents, such as data collection, data storage, data transmission network, data analysis system, etc. Through the integration of data resources, colleges can achieve a highly integrated information processing platform, which will give full play to the data mining and data analysis capabilities of big data. Through the integration of data resources, the efficiency and value of data can be effectively improved, which will support the management decision-making of colleges.

\section{Conclusion}

Big data has changed the thinking and governance mode of higher education. Big data is not enough, which will directly affect the governance of big data. With the implementation of the national big data strategy, China's laws and regulations will be gradually improved. By improving the quality of big data, colleges can improve the accuracy and speed of data information, which will increase the value of data. Through the reform of big data technology and thinking, the governance mode can be more efficient and intelligent.

\section{References}

1. Liu W. The impact of big data on higher education management and optimized management (in Chinese). Economic and Trade Practice 2018; (22): 263.

2. Shi H. Analysis on the reform of higher education management mode in the context of big data (in Chinese). Science and Education Literature Collection 2018; 425(6): 138-139.

3. Ping H, Li P. On the innovation of higher education management system in big data (in Chinese). China High Tech Zone 2017; (18): 64+66.

4. Zhang X. Research on big data in the field of higher education. Shandong University of Science and Technology (Social Science Edition) 2016; 18(6): 103-109. doi: 10.3969/j.issn.1008-7699.2016.06.015.

5. Li Y, Chen W, Zhang S. Big data in higher education (in Chinese). Journal of Electronic Science and Technology 2018; 20 (2):10 - 18.

6. $\mathrm{Xu} \mathrm{X,} \mathrm{Zhao} \mathrm{X,} \mathrm{Xiao} \mathrm{H,} \mathrm{et} \mathrm{al.} \mathrm{Application} \mathrm{of} \mathrm{big} \mathrm{data} \mathrm{in} \mathrm{undergraduate} \mathrm{teaching} \mathrm{evaluation.} \mathrm{Higher} \mathrm{Engineering}$ Education 2017; (1): 127-132. 